\title{
Economic Impact of Antidiabetic Medications and Glycemic Control on Managed Care Organizations: A Review of the Literature
}

\author{
JENNIFER M. STEPHENS, PharmD, BCPS; MARC F. BOTTEMAN, MSc, MA; and JOEL W. HAY, PhD
}

\begin{abstract}
OBJECTIVE: To review the recent literature (January 2000-November 2005) regarding the impact of antidiabetic medications and glycemic control on the overall costs of care for patients with diabetes in U.S. managed care organizations (MCOs).

SUMMARY: The pharmacy component accounts for typically $20 \%$ to $30 \%$ (full range, $10 \%-65 \%$ ) of overall costs for MCO patients with diabetes. About $30 \%$ of pharmacy expenses are directly related to glycemic control, while the balance is spent on the management of macrovascular and microvascular complications related to diabetes and other common comorbidities such as hypertension and hyperlipidemia. Cost offsets and/or cost savings have been shown with the initiation of insulin therapy, including the use of newer short-acting insulins. Increasing medication possession ratios for antidiabetic medications (including insulins) are correlated with reduced overall health care costs, particularly reductions in hospitalization rates. Patients with diagnosed diabetes not receiving medications have significantly increased health care resource utilization. We identified 8 studies that indicatred that improvements in glycemic control lower overall per-patient direct costs within MCOs.
\end{abstract}

CONCLUSIONS: The literature to date suggests that improving glycemic control and antidiabetic medication persistence reduce overall medical costs for patients with diabetes in managed care plans. Continued expansion of antidiabetic medication options will place increasing pressure on MCOs to assess the return on investment for newer pharmacotherapies. Routine measurement of economic and quality-of-life outcomes alongside clinical outcomes will become necessary for assessing the total value that new antidiabetic medications provide and whether cost offsets to managed care exist. Appropriate use of antidiabetic medications, including medication compliance, is an important component in a strategy to achieve glycemic control and may improve outcomes for patients with diabetes.

KEYWORDS: Managed care, Diabetes, Economics, Review, Burden, Resource utilization, Cost of treatment, Trends, Medications, Glycemic control

J Manag Care Pharm. 2006;12(2):130-42 $\square$ iabetes is a high-profile, costly disease to society and payers, including managed care organizations (MCOs). Most recent estimates put the overall annual economic burden of diabetes in the United States at more than $\$ 132$ billion. ${ }^{1}$ Since more than $60 \%$ of the U.S. population is covered by some form of managed care, ${ }^{2}$ MCOs certainly bear a substantial portion of the diabetes burden in this country.

Depending on patient mix, anywhere from 3\% to $10 \%$ of members of a typical MCO have diabetes, ${ }^{3}$ and these patients consume approximately $15 \%$ of health care budgets. ${ }^{4}$ At the individual patient level, managed care 3-year health care costs are a minimum of 2 times higher (with no complications) than age-matched controls without diabetes. ${ }^{5}$ Excess per-patient expenditures for diabetes averaged more than $\$ 3,400$ annually in 1994, with most of these excess costs related to hospitalizations and treatment of complications. ${ }^{6}$ In fact, costs of diabetes have increased over time for MCOs because of increased utilization of appropriate laboratory testing, outpatient services, and medications to manage diabetes. ${ }^{7}$ The increasing expenditures, along with the broad penetration of managed care in the United States, make diabetes a key disease for management of financial risk within an $\mathrm{MCO}$.

Over the past decade, national organizations such as the American Diabetes Association (ADA) have recommended specific target levels of glycemic control (hemoglobin Alc [Alc] $<7 \%$ ) for patients with diabetes to reduce microvascular and macrovascular complications related to hyperglycemia. ${ }^{8}$ These recommendations were based upon the landmark results of the 1993 Diabetes Control and Complications Trial in type 1 diabetes $^{9}$ and the 1998 United Kingdom Prospective Diabetes Study in type 2 diabetes, ${ }^{10}$ which demonstrated that intensive blood glucose control significantly lowers diabetes-related complications. In addition, it is now well established that intensive glucose control is cost effective over the long term, even for newly diagnosed patients. ${ }^{11}$ During the last decade, several new classes of oral antidiabetic medications, as well as multiple agents within a class, have become available, opening a variety of new opportunities for achieving the recommendations for more aggressive glycemic control.

The National Committee on Quality Assurance (NCQA), the ADA, and other national diabetes organizations advocating for early diagnosis and optimized glycemic control have spurred MCO investment of significant resources in disease management and pharmacotherapy to improve the management of their diabetic populations. While MCOs have invested significantly in aggressive diabetes management, the overall public health 
and economic impacts of these investments remain to be fully appreciated and investigated. Understanding the impact of the investment is important as the diabetes epidemic grows and as new medications become available.

The objective of this review was to synthesize the recent literature regarding the impact of antidiabetic medications and glycemic control on the overall costs of care for patients with diabetes in MCOs. Ultimately, our hope is that a better understanding and appreciation of the value associated with pharmacotherapy as a component of glycemic control will be useful as decision makers for diabetes management adapt their strategies, particularly as the diabetes pharmacologic armamentarium continues to expand.

\section{Methods}

We conducted a systematic literature review focused on the recent economic and resource utilization burden of diabetes in U.S. MCOs, with specific emphasis on antidiabetic medications and glycemic control. Research topics for the review included general burden and cost of diabetes to MCOs, pharmacy utilization patterns for patients with diabetes, impact of diabetes medication on resource utilization (including oral agents, insulin, insulin-related hypoglycemia, and persistence with therapy), the link between glycemic control and costs, and whether investments in pharmacotherapy to achieve glycemic control provide cost offsets to managed care.

The primary electronic database search was conducted in MEDLINE and was limited to English-language articles published from January 2000 through November 2005. The review focused on the past 5 years in order to identify the most recent economic data and trends for the current standards of care. The core search terms were "diabetes and managed care" with the following terms added for specificity: "economics," "costs," "medications," "cost drivers," "financial trends," and "complications."

In addition to the basic MEDLINE search, attempts were made (using the same search terms) to ensure that all potentially relevant information was identified by (1) searching sources represented through MEDLINE's "related articles/links" feature, (2) searching abstract archives from the ADA and the International Society for Pharmacoeconomics and Outcomes Research (ISPOR), (3) searching the Web sites of the NCQA and the Pharmaceutical Research and Manufacturers of America, and (4) using common Internet search engines (Google, Yahoo) to find abstracts, research reports, and information not otherwise identified. Finally, manual reviews of the subject index of the Journal of Managed Care Pharmacy and the bibliographies of relevant retrieved references were also conducted.

The combined MEDLINE and supplemental search strategies resulted in more than 500 abstracts, which were imported into a reference manager database and independently screened by 2 authors to assess relevance. An abstract was deemed relevant and the article retrieved in full text if it had information that addressed diabetes medication utilization within a managed care setting, including prescribing trends, relationship between cost and glycemic control, health care resource utilization patterns, cost information by various areas of care, or overall costs for various medication strategies. Abstracts were excluded if the primary topic of the paper was mental health comorbidities with diabetes, gestational diabetes, or impact of diabetes on employers.

After detailed abstract review, approximately 110 articles were selected and retrieved in full text. Because the focus of the search was on economic impact within MCOs, we selected 37 articles that specifically reported costs or resource utilization trends as key, relevant papers for inclusion in the Results section of this review. These key papers were specifically designed to answer issues related to the research questions and most commonly utilized longitudinal retrospective claims data analyses. Another 31 articles did not meet strict inclusion criteria but did contain information relevant to support background or discussion of the results; among these were studies reporting trends in medication use, studies related to glycemic control or disease management without specific cost data, and studies published prior to the year 2000 that were identified from manual review of bibliographies that reported economic or resource utilization data useful for comparisons with more recent data in this review.

We retrieved articles even if there appeared to be a small chance that they would address economic or resource utilization issues; thus 42 out of 110 retrieved articles were excluded. The most common types of papers excluded were those identified as potentially relevant from the abstract (e.g., the abstract had mentioned economics or resource utilization) but, as we determined by reviewing the full paper, focused only on clinical data. For example, most of the managed care literature on disease management programs (DMPs) focuses on reporting clinical outcomes and performance measures, without linking clinical end points to the economic or resource utilization data at the patient level for overall cost of care. Other common reasons for exclusion of papers were that the study population was not managed care (e.g., the paper made extrapolations to MCOs, but the retrospective data set or study population used was not managed care) or the article was a general review paper without reporting specific economic data.

Where possible, we identify the type of cost reported in the articles (charges, reimbursements, claims paid, total vs. diabetesattributable). Cost information is reported as it appeared in the original articles to avoid an artificial presentation of results given changing patterns of care and the long time frames of data analysis (>10 years in some studies); however, as an aid for the reader, we used the medical component of the Consumer Price Index to inflate original costs to current 2005 values. The 2005 inflated values are reported in parentheses next to the original 
TABLE 1 Breakdown of Total Direct Costs for Enrollees With Diabetes in MCOs

\begin{tabular}{|c|c|c|c|c|c|}
\hline \multirow[b]{2}{*}{ Type of MCO and Year of Data } & \multicolumn{5}{|c|}{ Component of Care (\%) } \\
\hline & Inpatient & ER & Outpatient & Pharmacy & SNF \\
\hline Northeast MCO, $2001^{12}$ & 58 & - & 42 & - & - \\
\hline Midwest MCO, $2001^{17}$ & 44 & - & 48 & - & 5 \\
\hline Urban Midwest HMO, $2001^{7}$ & & Medical $\$: 47$ & & 53 & - \\
\hline Rural Appalachia HMO, $2001^{7}$ & & Medical: 61 & & 39 & - \\
\hline Large California MCO, 1999-200118 & & Medical: 77-88 & & $12-23$ & - \\
\hline $\begin{array}{l}\text { Large national MCO, 1997- } 2000^{19} \\
\text { Preinsulin initiation } \\
\text { Postinsulin initiation }\end{array}$ & & $\begin{array}{l}\text { Medical: } 89 \\
\text { Medical: } 77\end{array}$ & & $\begin{array}{l}11 \\
23\end{array}$ & $\begin{array}{l}- \\
-\end{array}$ \\
\hline $\begin{array}{l}\text { Medicare HMO (North Carolina), } \\
\text { 1996-200220 }\end{array}$ & 20 & 20 & 50 & $<10 \S$ & - \\
\hline $\begin{array}{l}\text { Large national MCO, 1998-199921 } \\
\text { Insulin users only }\end{array}$ & 28-39 & 3 & $31-33$ & $28-36$ & - \\
\hline Large Midwest HMO, 1999*22 & $12-35$ & $0-3$ & $18-50$ & $30-65$ & - \\
\hline $\begin{array}{l}\text { Large Pacific NW HMO, } 199914 \\
\text { Diabetes, no CVD } \\
\text { Diabetes + CVD }\end{array}$ & $\begin{array}{l}31 \\
51\end{array}$ & $\begin{array}{l}- \\
-\end{array}$ & $\begin{array}{l}40 \\
28\end{array}$ & $\begin{array}{l}29 \% \\
21 \%\end{array}$ & $\begin{array}{l}- \\
-\end{array}$ \\
\hline Large Pacific NW HMO, $1995^{23}$ & $26-39$ & 1 & $22-33$ & $14-27$ & - \\
\hline $\begin{array}{l}\text { Capitated Northeast MCO } \\
\text { diabetes center, } 2002^{24}\end{array}$ & & Medical: 65 & & 35 & - \\
\hline National burden $\dagger, 2002^{1}$ & 44 & 2 & 20 & 19 & 15 \\
\hline $\begin{array}{l}\text { * Patients with no complications. } \\
\dagger \text { National burden estimates provided fo } \\
\text { † Medical represents nonpharmacy exp } \\
\text { \& Limited prescription coverage on drug } \\
\text { ER=emergency room; } C V D=\text { cardiovaso }\end{array}$ & $\begin{array}{l}\text { on with } \mathrm{MC} \\
\text { ombined for } \\
\text {; } \mathrm{HMO}=h\end{array}$ & $R$, and outpatien & 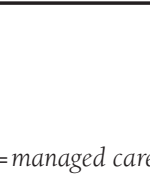 & 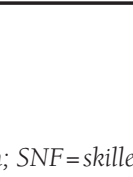 & $x^{2}$ \\
\hline
\end{tabular}

cost. Statistical significance of the results was reported where available.

\section{Results}

\section{Annual Costs of Diabetes Within MCOs [expressed in 2005 dollars]}

The average per-member (patient) annual cost for a typical mix of patients with diabetes is between $\$ 3,715$ [\$4,614 in 2005 dollars] and $\$ 5,760[\$ 6,532]$ in closed-model health maintenance organizations (HMOs) or MCOs with some type of DMP, and may be as high as $\$ 7,000[\$ 9,046]$ without a DMP.,12-15 When compared with other diseases, diabetes is neither the least nor most expensive disease to MCOs on a per-patient basis. The annual average cost of diabetes per patient $(\$ 4,878$ [\$6,058]) was higher than asthma $(\$ 3,707[\$ 4,604])$ but was half that of the average annual cost for coronary artery disease (CAD, \$9,512 [\$11,814]) across old and new patients. ${ }^{16}$ This study, following patients the year before and after (1999-2000) implementation of a DMP, used predictive modeling from medical and pharmacy claims for total costs and was not limited to disease-specific costs. This study may have failed to exclude diabetes patients from the CAD analysis, thus inflating the burden of CAD as a single diagnosis. For comparison, Nichols and Brown (2002) reported the annual cost of cardiovascular disease (CVD) with no diabetes at \$6,396 [\$8,257] and CVD with diabetes at $\$ 10,172[\$ 13,132] .{ }^{14}$

For newly diagnosed patients without complications, overall costs are more than $50 \%$ lower than for the average patient with diabetes. ${ }^{14}$ In a large Michigan HMO, the baseline annual cost for a patient with no complications and diet-controlled diabetes was $\sim \$ 1,600[\$ 1,987]$ for male patients and $\sim \$ 2,100[\$ 2,608]$ for female patients. ${ }^{13}$

\section{Breakdown of Expenditures}

Within managed care, the top expenditure category for the broad diabetes population is typically inpatient care. For patients newly diagnosed with no complications, top expenditure categories are pharmacy and outpatient services. Breakdown of costs (as a percentage of total medical costs) within MCOs range as follows: inpatient, 12 to $58 \%$; outpatient, 18 to $50 \%$; and pharmacy, 10 to $65 \%$. By comparison, on the national level across all payers (including Medicare), major expenditures by 
category for patients with diabetes were inpatient care (44\%), nursing home care (15\%), outpatient care (20\%), and medications/supplies (19\%). ${ }^{1}$ Table 1 shows the breakdown of recent MCO overall direct costs that have been reported in the literature for patients with diabetes. $1,7,12,14,17-24$

\section{Pharmacy Utilization Patterns for Patients With Diabetes}

Several studies have described the general medication and health care resource utilization patterns in patients with diabetes in MCOs. The pharmacy component ranges from 10\% to $65 \%$ of overall costs for MCOs. Approximately 30\% of prescription costs are directly related to glycemic control, while the rest are for management of the macrovascular and microvascular complications of diabetes and common comorbidities such as hypertension and hyperlipidemia. ${ }^{23}$ Diabetes patients in MCOs often receive many medications. At a closed-model HMO, patients with diabetes received an average of 20 to 24 prescription medications annually for any reason (diabetes and comorbidities). ${ }^{25}$

Though MCOs may restrict use of new medications, enrollees in MCOs are significantly more likely to be treated with antidiabetic medications in the first place and are also more likely to receive newer, more progressive antidiabetic medications (such as the insulin sensitizers and newer sulfonylureas) compared with patients covered by regular indemnity health plans.$^{26}$ However, MCOs may also use member cost-sharing (copay) for medications, including oral diabetes medications, which may adversely affect persistence with oral antidiabetic medications. ${ }^{27}$

Glycemic control (achieving target Alc) is managed with a variety of agents, and the use of insulin is common. Across a variety of studies and types of MCOs, the proportion of diabetes patients receiving insulin typically ranges from 23\% to $32 \%$. $320,26,28,29$ This rate of insulin use has fallen from more than $40 \%$ in the mid-1990s with the entry of newer oral agents that improve insulin resistance and reduce insulin needs, as well as a surge in newly diagnosed patients that do not require insulin early in their disease. ${ }^{7}$ Similar trends were seen nationally across a variety of payers in the late 1990s, where insulin use decreased and the use of combination regimens of oral antidiabetic agents increased. ${ }^{30}$ Interestingly, glycemic control rates (Alc $<7 \%$ ) declined from $44.5 \%$ to $35.8 \%$ during this same time frame. ${ }^{30}$ Thus, despite a substantial growth in the number of therapeutic options available to treat diabetes in the last decade, a significant proportion of patients with diabetes were still not achieving glycemic goals.

A 5-year (data from 1997-2001) cross-sectional study reported a "snapshot" of drug use patterns each year at 2 HMOs and found that overall utilization of prescriptions for diabetes patients increased because of emphasis on achieving glycemic, blood pressure, and lipid goals. ${ }^{7}$ In this time frame, both overall drug and diabetes drug expenditures more than doubled in urban/suburban plans. Utilization of metformin, thiazolidine- diones (otherwise referred to as glitazones), multiple-drug diabetes regimens, cholesterol-lowering agents, and angiotensinconverting enzyme inhibitors or angiotensin receptor blockers more than doubled, while the use of insulin, sulfonylureas, and alpha-glucosidase inhibitors declined or remained stable. $^{7}$

Another study examined diabetes drug therapy trends using data from 1997 to 2000, of which more than 50\% of the patients were covered by some type of managed care. ${ }^{31}$ During this period, treatment with any insulin therapy (monotherapy or in combination) fell from approximately $22 \%$ to $18 \%$ of patients, insulin monotherapy fell from $18 \%$ to $13 \%$, and insulin therapy in combination with an oral antidiabetic agent essentially remained constant (5.8\%-5.9\%). For oral agents, the proportion of patients receiving monotherapy with sulfonylureas dropped from $35 \%$ to $26 \%$, yet the proportion receiving monotherapy with either metformin or a glitazone doubled. Combination therapies ( 2 or more drugs) increased by $>2$ to 8 times over the 4-year period. Use of 3 oral agents in combination, albeit low, increased 6-fold (0.5\%-3\%).

Drug therapy prescribing patterns in 1,085 MCO enrollees were examined over 36 months (1997-2000). ${ }^{32}$ The study population was starting its initial drug therapy and had high proportions of elderly persons ( $67 \%$ aged $>60$ years) and those with complications (76\%). Drug therapy patterns from initiation to 36 months found that $11 \%$ were receiving no drug therapy at the end of the study, 54\% were receiving oral monotherapy (down from $82 \%$ at initiation), $27 \%$ were receiving combination therapy (up from 6\%), and insulin monotherapy was down from $12 \%$ to $9 \%$. Despite escalation to combination therapies over 36 months, more than $80 \%$ of the population did not reach recommended glycemic goals, and mean Alc was essentially unchanged from the baseline to the end of the study. Though glycemic goals are difficult to achieve, it is not for lack of trying. Once patients initiate oral therapy, there appears to be frequent adjustment of the regimen, with most patients requiring at least 2 modifications to their regimen in the first 12 months of pharmacologic treatment. ${ }^{33}$

\section{Impact of Diabetes Medications on Resource Utilization and Costs}

The proportion of total costs spent on the pharmacy category in patients with diabetes has increased in recent years, in part because of emphasis on achieving glycemic targets; the use of newer, more expensive medications; and a trend toward multidrug strategies. Several MCO studies examined the relationship between total health care costs and antidiabetic drug regimens. These studies are generally not comparable, as patient population characteristics, time frames, and drug therapy comparisons were different. Nevertheless, they do provide valuable insight on the impact of medication on total cost of care within a managed care setting. 


\section{TABLE 2 Antidiabetic Medication Studies Assessing Managed Care Costs}

\begin{tabular}{|c|c|c|c|}
\hline Study/Year & Comparisons & Data and Methods & Key Findings* \\
\hline $\begin{array}{l}\text { Rosenblum and Kane } \\
2003^{19}\end{array}$ & $\begin{array}{l}\text { Preinsulin vs. } \\
\text { postinsulin initiation }\end{array}$ & $\begin{array}{l}\text { 1997-2000 MCO claims data } \\
\text { (medical, facility, pharmacy) } \\
\text { from 1,177 patients with T2D } \\
\text { aged 18-65 years with continuous } \\
\text { claims data } 9 \text { months before } \\
\text { and after start of insulin; } \\
\text { trend analysis on standardized } \\
\text { costs (plan payments) at 60-day } \\
\text { increments postinsulin }\end{array}$ & $\begin{array}{l}\text { Totals costs increased } 10 \% \text { in the first } 2 \text { months following } \\
\text { initiation of insulin; however, from month } 2 \text { through month } 8 \\
\text { costs decreased } 40 \% \text {. Costs were significantly lower at each time } \\
\text { point after the first } 2 \text { months, including pharmacy, medical, and } \\
\text { facility costs (all } P<0.001) \text {. Pharmacy costs did not return to } \\
\text { preinsulin levels; however, medical ( } P<0.003) \text {, facility }(P<0.013 \\
\text { and total costs }(P<0.002) \text { decreased below preinsulin levels by } \\
\text { months } 4-6 \text {. }\end{array}$ \\
\hline
\end{tabular}

Thiebaud et al.

2005 (abstract) ${ }^{35}$
Insulin users vs.

nonusers (oral

antidiabetic meds)

\section{1-2004 medical and} pharmacy pharmacy claims data for 369 patients with T2D enrolled in a single Midwest HMO; propensity score weighted regression to assess insulin on costs

Chen et al. $2005^{34}$
Insulin lispro vs. regular human insulin
2000-2001 MCO claims data for 6,436 subjects on insulin (30.6\% lispro, 69.4\% regular) during a 12-month follow-up; propensity score model methods; charges for hospital and outpatient services; acquisition price for drugs
Patients aged $>60$ years using insulin experience a reduction of $42 \%$ in total costs and $32 \%$ in ambulatory costs relative to other patients receiving oral antidiabetic agents (both $P<0.05$ ). Insulin patients aged 30-40 years have a 33\% reduction in total costs (NS), while those $40-60$ years have $4 \%-17 \%$ increases in effect of total costs (NS).

Pharmacy costs were higher for lispro users by \$212 [\$252] per year $(P<0.001)$, but this was offset by reduced hospitalization for cost savings of $\$ 2,286[\$ 2,713](P<0.011)$ in nondiabetes medical and total medical savings of $\$ 2,327[\$ 2,762](P<0.072)$ annually for insulin lispro users compared with regular insulin. Patients less likely to receive lispro were older, on oral medications, and had more comorbidities.
Hall et al. Insulin lispro vs.

$2003^{21} \quad$ regular insulin
1998-1999 medical and pharmacy Insulin lispro users at baseline were younger; more likely to claims data from 14 health plans have T1D, a history of insulin use, and fewer comorbidities; with 11,443 patients on insulin more likely to visit endocrinologists; and had lower total costs. (29.2\% lispro, $70.8 \%$ regular); After matching 1:1, lispro users had more office visits $(P=0.002)$ propensity score matched $1: 1, \quad$ and more prescriptions filled $(P=0.017)$ than regular insulin resulting in $>1,800$ pairs that users but fewer inpatient admissions $(P=0.003)$, lower were then followed for 12 months Overall cost for lispro users was \$216 [\$268] less per year (NS).

Stockl et al. $2003^{18}$
4 oral agent regimens:
- repaglinide monotherapy
- metformin monotherapy
- repaglinide+metformin
- metformin + glyburide

\author{
1999-2001 medical and \\ pharmacy claims data from \\ large West Coast MCO with \\ 44,367 subjects in 4 cohorts: \\ metformin $(n=26,535)$, \\ repaglinide $(n=500)$, \\ metformin+glyburide \\ ( $\mathrm{n}=17,160$ ); follow-up period \\ was 9 months
}

\section{Repaglinide provided cost offsets only when used in} combination with metformin. Mean total costs were: $\$ 8,924[\$ 10,593]$ for repaglinide + metformin, $\$ 9,448$ $[\$ 11,214]$ for metformin, $\$ 9,576[\$ 11,367]$ for metformin +glyburide, and $\$ 11,910[\$ 13,594]$ for repaglinide. Differences were not repaglinide + metformin $(n=172)$, statistically significant due to sample size and variability in costs.

* Costs updated to 2005 dollars in brackets [].

$H M O=$ health maintenance organization; $M C O=$ managed care organization; NS=nonsignificant; T1D=type 1 diabetes; T2D=type 2 diabetes.

\section{Intensity of Drug Therapy and Total Costs}

Two studies researched the relationship between antidiabetic classes of medication and total medical care expenditures in MCOs. ${ }^{22,23}$ In the first study, a large Midwest MCO reviewed its 25,000 members with diabetes and examined annual diabetes treatment costs by drug therapy. ${ }^{22}$ Annual total treatment costs (inpatient, outpatient, emergency room [ER], and pharmacy, including supplies) for those diabetes patients with no complications in 1999 ranged from $\sim$ \$600 [\$775] for no drug treat- ment to $\sim \$ 2,600[\$ 3,357]$ for those receiving 3 or more drugs in combination therapy. In newly diagnosed patients without complications, the pharmacy costs became a major component of their total expenditures (as much as 65\% in triple therapy [3 agents used in combination]).

An older study ${ }^{23}$ using California HMO data from the mid-1990s also found that overall costs increased as antidiabetic therapies were escalated. Nevertheless, the total contribution of diabetes medications to the overall enrollee cost was relatively 


\section{TABLE 3 Impact of Antidiabetic Medication Persistence on Managed Care Costs}

\begin{tabular}{|c|c|c|}
\hline Study/Year & Data Details & Relationship of Persistence to Total Costs and Resource Utilization* \\
\hline $\begin{array}{l}\text { Balkrishnan et al. } \\
200320\end{array}$ & $\begin{array}{l}\text { 1996-2002 claims data, } \\
\text { mid-Atlantic Medicare HMO, } \\
\mathrm{N}=775 \text {, aged } \geq 65 \text { years, } \\
\text { T2D, oral agents and/or insulin, } \\
1-5 \text { year follow-up ( } 2,450 \text { patient years })\end{array}$ & $\begin{array}{l}\text { Increased antidiabetic MPR was the strongest predictor of decreased total annual health care } \\
\text { costs. A } 10 \% \text { relative increase in antidiabetic MPR was associated with an } 8.6 \% \text { relative } \\
\text { decrease in total annual health care costs }(P<0.001) \text {, with sensitivity analyses suggesting that } \\
\text { cost savings may be as high as } 28 \% \text {, with a } 10 \% \text { relative increase in MPR. Reduced costs with } \\
\text { increased MPR held true for all agents, including insulin. }\end{array}$ \\
\hline $\begin{array}{l}\text { PhRMA } \\
200438\end{array}$ & $\begin{array}{l}\text { 1999-2001 claims data, } \\
\text { proprietary database of }>70 \text { plans, } \\
\mathrm{N}=46,000 \text {, age not specified, } \\
\mathrm{T} 2 \mathrm{D} \text {, new starts on oral agents, } \\
\text { 1-year follow-up }\end{array}$ & $\begin{array}{l}\text { The patients most persistent (top one third) with their antidiabetic medications had a } 40 \% \\
\text { reduction in hospitalization rates ( } 10 \% \text { vs. } 16 \% \text { ) compared with those with lowest persistence. } \\
\text { Patients with highest persistence had annual pharmacy costs that were } \$ 300 \text { [ } \$ 356] \text { higher } \\
\text { per patient, but this was offset by a } \$ 600 \text { [ } \$ 712] \text { per-patient savings on inpatient care. }\end{array}$ \\
\hline $\begin{array}{l}\text { Lau and Nau } \\
2004^{40}\end{array}$ & $\begin{array}{l}\text { 2000-2001 claims data; } \\
\text { Midwestern MCO; } \\
\text { N=900; aged >18 years; } \\
\text { T2D; oral agents, excluded insulin; } \\
\text { 1-year follow-up ( } 2000 \text { adherence } \\
\text { relationship to } 2001 \text { hospitalization) }\end{array}$ & $\begin{array}{l}\text { When } 2000 \text { MPR dropped below } 80 \% \text {, risk of } 2001 \text { hospitalization (diabetes or CV causes) } \\
\text { significantly increased (OR } 2.53 ; 95 \% \text { CI, } 1.38-4.64) \text { within a } 1 \text {-year time frame. } \\
\text { Rate of hospitalization increased from } 5.2 \% \text { to } 10.3 \% \text { when MPR was }<80 \%(P=0.01) \\
\text { with rate of hospitalization highest at } 14.8 \% \text { when MPR was }<40 \% \text {. }\end{array}$ \\
\hline $\begin{array}{l}\text { Curkendall et al. } \\
2005 \text { (abstract) }\end{array}$ & $\begin{array}{l}2000-2001 \text { claims data; } \\
\text { large } \mathrm{MCO} \text {; }=54,505 ; \\
\text { aged >18 years; overall }(P<0.001) \\
\text { T2D; oral agents, insulin not excluded; } \\
\text { 1-year follow-up; stratified by baseline } \\
\text { resource intensity }\end{array}$ & $\begin{array}{l}\text { Nonadherence to oral antidiabetic medications increased total and diabetes-attributable costs } \\
\text { for the most resource-intensive patients but did not increase average costs for the population. } \\
\text { For the } 70 \% \text { of patients with the highest diabetes-attributable costs, worsening adherence } \\
\text { increased the medical services portion of diabetes-attributable costs. }\end{array}$ \\
\hline \multicolumn{3}{|c|}{$\begin{array}{l}\text { * Costs updated to } 2005 \text { dollars in brackets [ ]. } \\
C V=\text { cardiovascular; } H M O=\text { health maintenance organization; } M C O=\text { managed care organization; } M P R=\text { medication possession ratio; OR=odds ratio; } \\
P h R M A=\text { Pharmaceutical Research and Manufacturers of America; } T 2 D=\text { type } 2 \text { diabetes. }\end{array}$} \\
\hline
\end{tabular}

small (5\%-13\%). Within the medication category, glycemic control medications for diabetes accounted for between $4 \%$ and $47 \%$ of the total pharmacy budget. Overall costs appeared higher for patients on insulin, but when their diabetes drugs were examined as a proportion of the overall cost and proportion of the pharmacy budget, drug costs were not the drivers (diabetes drugs were $6 \%$ of total costs and $\sim 30 \%$ of the pharmacy budget); inpatient care drove the costs for patients on insulin, indicating that these patients were further along in their disease progression and had more complications.

\section{Impact of Medications: Comparative Studies}

As summarized in Table 2, 5 studies using retrospective claims data addressed the impact of medication strategies on total diabetes treatment costs in managed care settings. ${ }^{18,19,21,34,35}$ Four studies were insulin-specific, evaluating the general cost impact of initiating insulin ${ }^{19,35}$ or the cost offsets associated with newer insulin formulations ${ }^{21,34}$; only 1 study examined specific oral medication strategies. ${ }^{18}$ As presented in more detail in Table 2, key findings from these studies were the following: (1) insulin initiation does not increase overall costs when considering a short-term perspective of 4 to 8 months but rather reduces costs by as much as $40 \%$ over the preinsulin period, ${ }^{19}(2)$ cost offsets with initiation of insulin may be specific to elderly populations, ${ }^{35}$ (3) increased pharmacy expenditures for new short-acting insulins are offset by medical cost savings and reductions in medical resource utilization, ${ }^{21,34}$ and (4) cost savings with oral medication strategies may be related to the specific combinations of medications used and not a single agent used alone. ${ }^{18}$

\section{Impact of Insulin-Induced Hypoglycemia}

Reluctance to use insulin for intensification of glycemic control often includes a fear of adverse events, particularly hypoglycemia. The incidence and economic impact of insulininduced hypoglycemia in MCOs has been reported in 2 studies. ${ }^{36,37}$ At a New England staff-model HMO, the incidence and resource utilization patterns of serious hypoglycemia (defined as a hypoglycemic episode requiring care in an ER or hospital) were evaluated retrospectively in 1,113 patients, aged 20 to 64 years, who used insulin monotherapy from 1993 to $1997 .{ }^{36}$ The overall incidence of serious hypoglycemia during the study period was $\sim 5$ episodes per 100 patient-years (95\% confidence interval $[\mathrm{CI}], 4.14-6.00)$ and was higher (5.71-8.23 episodes per 100 patient-years) in younger female patients (aged 20-44 years). Ninety-four percent of cases were managed in the ER.

Another study at a large Midwestern MCO followed 2,118 patients for 6 years (1992-1998) who were prescribed some type of insulin regimen. ${ }^{37}$ Hypoglycemia significant enough to warrant medical attention occurred in 16\% of patients receiving insulin, with 7.1 episodes per 100 patient-years. Overall mean 
cost per episode was $\$ 1,186$ [\$1,583] (range \$181-\$4,924 [ $\$ 242-\$ 6,574]$ ) or $\sim \$ 7$ per member per month (PMPM) [ $\$ 9$ PMPM]. Costs were driven by the hospitalizations occurring in $15 \%$ of episodes but representing more than $60 \%$ of the total costs to the MCO. Treatment facility frequency and associated mean cost per episode were as follows: hospital, 15\% (\$4,924 $[\$ 6,574]) ; \mathrm{ER}, 30 \%(\$ 812[\$ 1,084])$; and physician office, $50 \%$ (\$181 [\$242]).

\section{Impact of Antidiabetic Medication Persistence}

Several important studies, summarized in Table 3, have linked increased persistence with/adherence to antidiabetic medications to reduced health care utilization/costs in MCO settings. ${ }^{20,38-40}$ These studies, all using managed care claims data, demonstrate that the increase in medication possession ratios for antidiabetic medications (including insulins) is correlated with reduced overall health care costs, ${ }^{20}$ particularly with reductions in hospitalization rates. ${ }^{38,40}$ In addition, patients with diagnosed diabetes not receiving medications have significantly increased health care resource utilization. ${ }^{38}$ And finally, in patients with high baseline diabetes-attributable costs, worsening adherence predicts an increase in diabetes-related medical costs. ${ }^{39}$

\section{Link Between Glycemic Control and Costs}

The relationship between improved glycemic control and reduced costs in MCOs has been fairly well established in a variety of studies, including retrospective claims analyses, studies of antidiabetic medication persistence, and evaluations of the overall impact of DMPs. We identified 4 published articles ${ }^{41-44}$ and 1 study in abstract form ${ }^{45}$ that were specifically designed to address the relationship between glycemic control and total costs. Three supportive studies were also identified that reported relevant information. . $^{4,46,47}$

In the first study, a claims data analysis from a New England HMO compared patients with good (Alc <8\%), fair (Alc 8-10\%), and poor glycemic control (Alc $>10 \%){ }^{41}$ They found a statistically significant inverse relationship between the level of control and the likelihood of inpatient admissions on both an adjusted (for each patient's follow-up time) and unadjusted basis $(P<0.01$ for both). Patients with poor control had the highest corresponding charges for inpatient admissions (over a 3-year timeframe) primarily related to short-term complications (e.g., hyperglycemia or hypoglycemia, infections, electrolyte disturbances). The study was designed to assess short-term impact; thus, it did not link long-term complications to glycemic control.

Another claims data analysis at a Pacific Northwest $\mathrm{HMO}$ compared patients with $1 \%$ absolute Alc reduction with unimproved patients and linked the glycemic control to cost savings from reduced complications over 4 years ${ }^{42}$ In this study, cost savings were seen in all patients improved but occurred even for those already close to glycemic targets and for those with baseline complications or CVD ( $\$ 800$ savings annually for those with complications or CVD vs. $\$ 400$ annually for those with no baseline complications). During the study years of 1994 to 1997, the total per-patient costs were consistently lower in the improved group (by $\$ 685-\$ 950$ [\$944-\$1,309] per patient per year) and were significantly lower in years 1995 to 1997 ( $P<0.01)$.

Two recent additional studies provided data on the relationship between glycemic control and costs in managed care settings in both short-term and intermediate time frames. ${ }^{43: 45}$ The first study examined the 1-year impact of glycemic control on direct medical costs in a large national health plan. ${ }^{43}$ Patient medical claims were analyzed using 2 groups for comparison: those at their target Alc level $(\leq 7 \%)$ and those above the target. After controlling for confounding variables, the patients above target had $30 \%$ higher medical costs at 1 year $(P<0.01)$. A second study also used managed care claims data from a Southeastern health plan of $>10,000$ patients with diabetes in a longitudinal analysis of up to 43 months. ${ }^{45}$ Patients were stratified into good (Alc $\leq 7 \%$ ), fair $(\mathrm{Alc}>7 \%)$, and poor (Alc $>9 \%$ ) glycemic control. Patients with good glycemic control had total diabetes attributable costs that were $20 \%$ and $24 \%$ lower $(P<0.05)$ than the fair and poor glycemic control groups, respectively.

Finally, Gilmer and colleagues (2005) updated their earlier landmark analysis ${ }^{48}$ of the relationship between incremental changes in baseline Alc level and subsequent 3-year total costs in a Minnesota health plan with more than 600,000 members. ${ }^{44}$ For this study, multivariate regression analysis was conducted on prospective patient survey, baseline laboratory, and 3-year retrospective claims data (1999-2002) from 1,694 patients with complete information. After controlling for age, sex, diabetes duration, education, and income, they found that Alc levels higher than $7.5 \%$ continued to be a significant independent predictor of total cost $(P=0.015)$ although stronger predictors of total costs were coronary heart disease, hypertension, and depression.

Another study ${ }^{24}$ demonstrated that higher total health care costs were significantly related to both higher Alc levels and higher disease severity index or a larger number of comorbidities. The cost difference was more than $\$ 600$ [ $\$ 775$ ] for a change in HbAlc from 8.7 to $7.2 \%$ with 0 to 1 comorbidities but was more than $\$ 16,000[\$ 20,656]$ different with 4 comorbidities.

Finally, some evaluations of DMPs of various types show a reduction in health care resource utilization and costs with improved glycemic control. For example, a single health plan DMP produced an absolute decrease in Alc levels of $0.5 \%$ $(8.2 \%-7.7 \%)$, a $22 \%$ decrease in hospital admissions, a $34 \%$ decrease in hospital length of stay, and a 12\% decrease in PMPM costs only 9 months after program initiation. ${ }^{46}$ An academic health system similarly found that its DMP produced a more than $1 \%$ absolute reduction in Alc (8.51\%->7.41\%), which was associated with a $\$ 108$ [ $\$ 128$ ] PMPM cost reduction, or an annual savings of $\$ 1,294$ [\$1,536] per member with diabetes. ${ }^{12,47}$ And finally, a Midwestern HMO found limited 
TABLE 4 Economic Value of Glycemic Control

\begin{tabular}{|c|c|c|c|}
\hline Study/Year & Data Details & Comparison/Change in Alc & Annual Cost Savings Per Patient $(\$)^{*}$ \\
\hline $\begin{array}{l}\text { Steffens } \\
2000+46\end{array}$ & $\begin{array}{l}\text { 1998-1999 } \\
\text { Total costs } \\
\text { Administrative data } \\
\mathrm{N}=10,000 \text {; any diabetes }\end{array}$ & $\begin{array}{l}8.2 \%->7.7 \% \\
\text { Before/after DMP }\end{array}$ & $672[868]$ \\
\hline $\begin{array}{l}\text { Menzin et al. } \\
2001 \neq 41\end{array}$ & $\begin{array}{l}\text { 1994-1998 } \\
\text { Inpatient charges only } \\
\text { Claims data; any diabetes } \\
\mathrm{N}=2,394 \text {; aged }>35 \text { years }\end{array}$ & $\begin{array}{l}\text { Good control }(<8 \%) \text { vs. } \\
\text { Fair control }(>8 \%-10 \%) \text { vs. } \\
\text { Poor control }(>10 \%)\end{array}$ & $\begin{array}{l}136 \text { [182]: all patients, fair->good } \\
690 \text { [921]: all patients, poor->good } \\
400 \text { [534]: w/complications, fair->good } \\
1983 \text { [2,647]: w/complications, poor->good }\end{array}$ \\
\hline $\begin{array}{l}\text { Wagner et al. } \\
2001 \S^{42}\end{array}$ & $\begin{array}{l}\text { 1994-1997 } \\
\text { Total costs } \\
\text { Claims data; any diabetes } \\
\mathrm{N}=4,744 \text {; aged }>18 \text { years }\end{array}$ & $\begin{array}{l}\text { Improved ( } 1 \% \text { or more } \\
\text { reduction in } A l c) \text { vs. } \\
\text { Unimproved }\end{array}$ & $\begin{array}{l}\text { 685-950 [944-1,309]: all patients } \\
\text { 802-882 [1,105-1,215]: complications or CVD } \\
438 \text { [604]: no complications }\end{array}$ \\
\hline $\begin{array}{l}\text { Rosenzweig et al. } \\
2002 \uparrow 24\end{array}$ & $\begin{array}{l}1999 \\
\text { Total costs } \\
\text { Chart review + claims data } \\
\text { N=697; T1D-68\%, T2D-32\% }\end{array}$ & $8.73 \%->7.22 \%$ & $644[831]$ \\
\hline $\begin{array}{l}\text { Oglesby et al. } \\
2005 \text { abstract||45 }\end{array}$ & $\begin{array}{l}\text { 1998-2003 } \\
\text { Total diabetes-attributable costs } \\
\text { Claims data } \\
\mathrm{N}=10,780 \text {; with T2D }\end{array}$ & $\begin{array}{l}\text { Good control }(\leq 7 \%) \text { vs. } \\
\text { Fair control }(>7 \%-\leq 9 \%) \text { vs. } \\
\text { Poor control }(>9 \%)\end{array}$ & $\begin{array}{l}269 \text { [293]: fair } \rightarrow \text { good } \\
333 \text { [363]: poor } \rightarrow \text { good }\end{array}$ \\
\hline $\begin{array}{l}\text { Shetty et al. } \\
\text { 2005qा43 }\end{array}$ & $\begin{array}{l}\text { 2002-2003 } \\
\text { Diabetes-related total costs } \\
\text { Claims data } \\
\mathrm{N}=6,780 \text {; with T2D }\end{array}$ & $\begin{array}{l}\text { Continuously at target }(\leq 7 \%) \text { vs. } \\
\text { Not at target }\end{array}$ & $\begin{array}{l}369 \text { [402]:predicted/regression } \\
409 \text { [446]: mean-diabetes related }\end{array}$ \\
\hline $\begin{array}{l}\text { Sidorov et al. } \\
2002 \uparrow 47\end{array}$ & $\begin{array}{l}\text { 1999-2001 } \\
\text { Total paid charges } \\
\text { Chart review + claims data } \\
\mathrm{N}=6,799 \text {; any diabetes }\end{array}$ & $\begin{array}{l}8.51 \% \text { vs. } 7.41 \% \\
\text { No DMP† vs. DMP }\end{array}$ & $1,294[1,536]$ \\
\hline $\begin{array}{l}\text { Gilmer et al. } \\
2005 \# 44\end{array}$ & $\begin{array}{l}1999-2002 \\
\text { Total costs; Medicare rates } \\
\text { Survey + chart review + claims } \\
\mathrm{N}=1,694 \text {; any diabetes }\end{array}$ & $\begin{array}{l}\text { Baseline Alc } 1 \% \text { change } \\
\text { increments and cost impact }\end{array}$ & $\begin{array}{l}458 \text { [519]: } 10 \%->9 \% \\
434 \text { [492]: } 9 \%->8 \%\end{array}$ \\
\hline \multicolumn{4}{|c|}{ 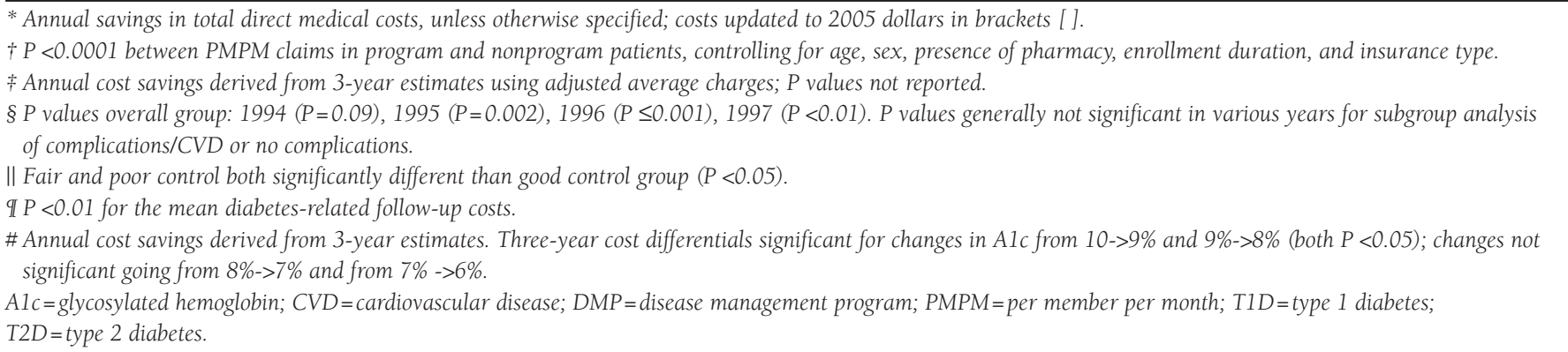 } \\
\hline
\end{tabular}

short-term cost savings from its DMP but estimated that the improved Alc levels produced from the program had a value related to improved length and quality of life of $\$ 31,000$ $[\$ 33,790]$ per patient achieving a $1 \%$ absolute reduction in Alc. ${ }^{12}$

Table 4 provides a summary of the reported annual perpatient economic value of glycemic control across the variety of studies discussed in this section. ${ }^{24,41-47}$

\section{Discussion}

This review provides a unique assessment of published literature reporting economic or resource utilization outcomes for patients with diabetes enrolled in managed care. Our findings suggest that, despite concerns of rising drug costs, the pharmacy costs have not been the driver of overall diabetes costs to MCOs. In addition, the pharmacy component is dominated by 
medications to treat CVD and other complications/comorbidities of diabetes, while only $\sim 30 \%$ of medications are related to glycemic control. Furthermore, the recent published comparisons of insulin in MCO settings suggest that higher pharmacy costs associated with starting insulin or using newer insulin formulations may be offset by medical cost savings within 1 year or less.

Most importantly, the results of this review suggest that there are potential overall cost savings to managed care plans from improving glycemic control and antidiabetic medication persistence, regardless of the specific medications used. These cost savings occurred despite additional spending in areas such as pharmacy for patients who achieved goals. In most studies, the cost offsets occurred from reduced inpatient admissions. Cost savings occurred even for patients already close to their goals who were making small changes (e.g., those going from an Alc level of $8 \%$ to $7 \%$ ).

Given these interesting findings between glycemic control and costs, it is worth discussing one older (pre-2000) study not included in the results. This landmark study in a Midwestern HMO found that charges for medical care from 1993 to 1995 were related to the level of glycemic control the year before (in 1992) ${ }^{48}$ Charges significantly increased for every absolute $1 \%$ increase above an Alc of $7 \%$. Compared with a person with an Alc of $6 \%$ (normal level), every additional $1 \%$ increase in Alc above this level resulted in cumulative charge increases of approximately $4 \%$ for $\mathrm{Alc}=7 \%$ ( $P=$ not significant), $10 \%$ increase for $\mathrm{Alc}=8 \%(P<0.05), 20 \%$ increase for $\mathrm{Alc}=9 \%$, $(P<0.01)$, and $30 \%$ higher charges for $\mathrm{Alc}=10 \%(P<0.01)$. This study also found that the cost savings differential for even modest Alc reductions ( $8 \%$ to $7 \%$ ) was $~ 3.5$ times higher in patients with diabetes plus comorbidities (heart disease and hypertension) compared with those with diabetes only. ${ }^{48}$ The finding that higher cost savings with glycemic control are achieved in sicker patients may also be consistent with Goetzel's review, ${ }^{49}$ which reported that glycemic control measures in prediabetes (less sick) did not produce a positive return on investment. Studies presented in this review suggest annual cost savings from improved glycemic control were more than double in patients with baseline complications than in patients without complications, indicating that investment in the sickest patients is worthwhile.

The direct 3-way link between investments in antidiabetic medications, improved glycemic control, and reduced costs has not been established, but some study results suggest this relationship. Oral antidiabetic medication adherence (with sulfonylureas) has been linked to improved glycemic control, ${ }^{50}$ and the series of studies described in this review show that increased antidiabetic drug persistence reduces total utilization and overall costs in short and intermediate terms. ${ }^{20,38-40}$ Thus, it may be reasonable to conclude from these studies that more persistent patients had better glycemic control and that appropriately used medications can reduce overall costs in managed care settings. However, limitations inherent in analyses of retrospective data may make the identification of unobservable biases difficult, ${ }^{51}$ as it is likely that people with unobservable propensity toward more healthful lifestyles are also more likely to comply with therapy and have better glycemic control and lower costs.

\section{Implications for Managed Care}

The relationship between improved glycemic control and reduced cost is fairly well established; however, implementing the appropriate interventions to achieve glycemic control in patients with diabetes continues to be a challenge for managed care. The NCQA estimates that failing to deliver recommended care for diabetes in managed care results in the following annual costs: 13,600 avoidable deaths, $\$ 178$ (\$194) million in avoidable hospital costs because of heart attack and stroke in patients with uncontrolled diabetes, and 11.6 million avoidable sick days. Surprisingly, the proportions of patients who still have poor glycemic control (Alc >9.5\%) were 25\% in Medicare managed care, $34 \%$ in commercial MCOs, and as high as $48 \%$ in Medicaid managed care..$^{52}$

Emerging reports indicate some improvement in glycemic control in recent years. At the national level, the National Health and Nutrition Examination Survey (NHANES) analysis from 2001 to 2002 found that $\sim 50 \%$ of patients were at goal $(\mathrm{HbAlc}<7 \%)^{53}$ compared with $36 \%$ of patients in the 1999 to 2000 NHANES data set. ${ }^{30}$ A California HMO recently reported that the proportion of its patients achieving recommended glycemic control had improved from 30\% in 1999 to 2000 to more than 50\% in 2004 because of more intensive drug regimens, including combination therapy. ${ }^{54}$ Though improvements have occurred over the last 4 years, nearly half of all patients with diabetes are still not at recommended glycemic goals.

There are many likely reasons for the continued lack of glycemic control; clearly, diabetes is a complex and challenging disease with no silver bullet for achieving success. There are a number of issues that come into play with the general lack of glycemic control across managed care. MCOs have been at the forefront of proactively managing diabetes through a variety of "disease management" initiatives, including programs targeting clinicians and patients. Part of the incentive for this focus on diabetes has been the Health Plan Employer Data and Information Set (HEDIS) performance measures, which allow comparison of managed health plans.

The HEDIS performance measures focus on frequency of measuring clinical parameters (blood pressure, lipids, Alc) as a proxy for quality of care, but measurement does not necessarily result in improved Alc levels. For example, a review of Medicare managed care plans in Oregon showed that, while HEDIS performance rate for Alc testing was $87 \%$, two thirds of the patients were not at recommended glycemic goals, with $24 \%$ in very poor control $(>9.5 \%) .{ }^{55}$ Similarly, a large Southwestern HMO found that, while Alc testing rates were 
$77 \%$, only $29 \%$ of those receiving antidiabetic medications met their glycemic goal ${ }^{56}$ Similar problems occur with not achieving blood pressure goals in diabetes. ${ }^{57}$

Not surprisingly, DMPs have limited success when the focus is on improving the numbers of tests performed. ${ }^{58}$ Programs associated with the greatest improvements in Alc levels include pharmacist evaluation and counseling, medication adjustment, and physician/patient interactions. ${ }^{58,59}$ Despite limitations with DMPs, a recent survey of programs in health plans covering more than 15 million members found that diabetes DMPs were the most frequently implemented (compared with other diseases) and that the average return on investment for MCOs was approximately 2 to $1 .{ }^{60}$

\section{Investment in Pharmacotherapy}

Another important issue related to the lack of glycemic control is a "silo" mentality on the pharmacy component of the costs of care for patients with diabetes (e.g., focus on drug budget impact without considering potential cost offsets in medical resource utilization). As our review indicates, only about 30\% of the pharmacy costs for patients with diabetes are related to glycemic control, with the majority of costs related to managing comorbidities and complications. In addition, there is now substantial evidence that the investment in diabetes drug therapy provides cost offsets, particularly reductions in inpatient care. Yet, surprisingly, more patients than ever are not being treated with any drug therapy for their diabetes. $32,38,45$

From 1990 to 2001, there was a rapid shift toward oral medication combinations and a reduction in insulin use. ${ }^{7,30,61}$ One might ask whether the reduction in insulin use in the 1990s could have slowed progress in population glycemic control. However, patients most likely to achieve glycemic goals are using insulin in combination with other oral medications. ${ }^{54}$ Newer formulations of insulin are now emerging and will continue to emerge ${ }^{62}$ Current trends in insulin use are difficult to ascertain using peer-reviewed literature because of lag times in publication of study results. However, market research information indicates that the pendulum is now swinging back toward insulin, with insulin analogs primarily driving the growth in the insulin market at more than 5\% annually and oral agents showing declines. ${ }^{63,64}$ While recent insulin studies discussed in this review have shown positive clinical and economic results, ${ }^{19,21,34,35}$ additional studies will be continually needed as new insulin options increase in the next few years. These studies suggest that restrictions placed on newer insulin therapies based solely on drug acquisition price may not be defensible without assessment of the entire cost impact of a drug on other medical expenditures (inpatient and outpatient care). Outcomes studies will help determine if newer insulin formulations and delivery systems will improve glycemic control and economic outcomes for MCOs.

The current economic burden of diabetes to managed care is accelerating. Over the past decade, the number of adults in the United States diagnosed with diabetes has increased by more than $35 \%$, and the age at diagnosis has decreased by an average of 6 years, from 52 to 46 years. ${ }^{65}$ The obesity epidemic and the continued aging of the U.S. population will also amplify the costs of diabetes to the health care system. ${ }^{66,67}$ Investments in pharmacotherapy and lifestyle interventions for patients with prediabetes have not produced a positive return on investment. ${ }^{49}$ However, for patients with diagnosed diabetes in managed care plans, there does appear to be a link between glycemic control and lower overall costs, demonstrated both in this review and other papers. ${ }^{60}$

Given the favorable economic impact of achieving glycemic control, MCOs will need to continue to evaluate the way that medications are managed. Managed care's continued investment in drug therapies to achieve glycemic control may improve quality of care and possibly reduce overall costs in the future. The Veterans Affairs system found that as their national annual medication expenditures increased from 1994 to 2000 for patients with diabetes, so did glycemic control. ${ }^{68}$ New research must be conducted to better understand the most recent economic impact of medications over the last 2 to 3 years. Furthermore, the benefits of new products in terms of glycemic control must be weighed along with their safety profiles and potential for rare, severe adverse events (e.g., the glitazones, muraglitazar).

\section{Limitations}

Key limitations of this review include the lack of information on the economic impact of the newest medications marketed in the past several years because of the common lag times associated with conducting and publishing research. Thus, the impact of newer medications is underrepresented; however, we attempted to address this limitation through review of abstracts presented at key professional meetings, including those of the ADA and ISPOR. Likewise, given publication lag time, much of the literature published between 2000 and 2005 uses older claims data with dates of service often before 2001.

Since our search terms and focus were on economic and resource utilization issues, our study eliminated much of the disease management literature reporting primarily clinical outcomes, which could have potentially biased the results. In addition, many of the studies reviewed reported only descriptive point estimates of cost savings with improved glycemic control, and these estimates are subject to statistical uncertainty. The potential weaknesses of the study designs may also lead to a favorable bias toward the benefits of medication use and glycemic control. Nevertheless, the review represents the current state of managed care literature in this area. Newer studies should attempt to correct for some of the potential sample selection bias issues using appropriate econometric methods in future retrospective data analyses..$^{51}$ 


\section{Conclusions}

The recent managed care economic literature suggests that improving glycemic control and antidiabetic medication persistence results in lower overall medical costs for patients with diabetes in managed care plans. Continued expansion of antidiabetic medication options will place increasing pressure on MCOs to assess the return on investment for newer pharmacotherapies. Routine measurement of economic and quality-of-life outcomes alongside clinical outcomes will become necessary for assessing the total value that new antidiabetic medications provide and whether cost offsets to managed care exist. Novel insulin therapies will continue to be an area of increasing focus and research given the recent studies suggesting overall cost savings (even in the short term) for newer agents, with reduced adverse events and improved patient compliance.

Appropriate use of antidiabetic medications, including medication compliance, is an important component in the strategy to achieve glycemic control and may improve outcomes for patients with diabetes. Whether managed care's significant investments in pharmacotherapies over the past 5 years have produced broad cost offsets and/or cost savings remains unclear. This question will probably continue to be addressed on a case-by-case basis, using head-to-head comparisons to establish whether cost offsets occur for MCOs when newer medications and combination therapies are used to achieve glycemic control.

\section{DISCLOSURES}

Funding for this study was provided by Pfizer, Inc. and sanofi-aventis and was obtained by authors Jennifer M. Stephens, Marc F. Botteman, and Joel W. Hay. The authors disclose no potential bias or conflict of interest relating to this article. Stephens served as principal author of the study. Study concept and design were contributed by all authors. Data collection was the work of Stephens, with input from Botteman; data interpretation was primarily the work of Stephens, with input from Botteman and Hay. Drafting and revision of the manuscript was primarily the work of Stephens, with input from Botteman and Hay.

\section{REFERENCES}

1. Hogan P, Dall T, Nikolov P, American Diabetes Association. Economic costs of diabetes in the U.S. in 2002. Diabetes Care. 2003;26:917-32.

2. MCOL Managed Care Fact Sheets. Managed care national statistics 2004. Available at: http://www.mcareol.com/factshts/factnati.htm. Accessed June 15, 2005.

3. Sidorov J, Gabbay R, Harris R, et al. Disease management for diabetes mellitus: impact on hemoglobin Alc. Am J Manag Care. 2000;6:1217-26.

4. Bailey JE, Womeodu RJ, Wan JY, Van Brunt DL, Somes GW. Improvements in diabetes management and outcomes in a Medicaid managed care system. Tenn Med. 2001;94:425-30.

5. Ramsey SD, Newton K, Blough D, McCulloch DK, Sandhu N, Wagner EH. Patient-level estimates of the cost of complications in diabetes in a managedcare population. Pharmacoeconomics. 1999;16:285-95.

6. Selby JV, Ray GT, Zhang D, Colby CJ. Excess costs of medical care for patients with diabetes in a managed care population. Diabetes Care. 1997;20: 1396-402.
7. Nau DP, Garber MC, Herman WH. The intensification of drug therapy for diabetes and its complications: evidence from 2 HMOs. Am J Manag Care. 2004;10:118-23

8. American Diabetes Association. Standards of medical care in diabetes. Diabetes Care. 2005;28:S4-S36.

9. The Diabetes Control and Complications Trial Research Group. The effect of intensive treatment of diabetes on the development and progression of long-term complications in insulin dependent diabetes mellitus. N Engl J Med. 1993;329:977-86.

10. United Kingdom Prospective Diabetes Study (UKPDS) Group. Intensive blood-glucose control with sulphonylureas or insulin compared with conventional treatment and risk of complications in patients with type 2 diabetes (UKPDS 33). Lancet. 1998;352:837-53.

11. Eastman RC. Cost-effectiveness of treatment of type 2 diabetes. Diabetes Care. 1998;21:464-65

12. Lynne D. Diabetes disease management in managed care organizations. Dis Manag. 2004;7:47-60.

13. Brandle M, Zhou H, Smith BR, et al. The direct medical cost of type 2 diabetes. Diabetes Care. 2003;26:2300-04.

14. Nichols GA, Brown JB. The impact of cardiovascular disease on medical care costs in subjects with and without type 2 diabetes. Diabetes Care. 2002; 25:482-86

15. Brown JB, Nichols GA, Glauber HS, Bakst AW. Type 2 diabetes: incremental medical care costs during the first 8 years after diagnosis. Diabetes Care. 1999;22:1116-24.

16. Cousins MS, Liu Y. Cost savings for a preferred provider organization population with multi-condition disease management: evaluating program impact using predictive modeling with a control group. Dis Manag. 2003;6: 207-17.

17. Solberg LI, Maciosek MV, Sperl-Hillen JM, et al. Does improved access to care affect utilization and costs for patients with chronic conditions? Am J Manag Care. 2004;10:717-22.

18. Stockl K, Vanderplas AM, Nicklasson L. A comparison of costs for 4 oral antidiabetic regimens within a managed care population. Manag Care Interface. 2003;16:31-36.

19. Rosenblum MS, Kane MP. Analysis of cost and utilization of health care services before and after initiation of insulin therapy in patients with type 2 diabetes mellitus. J Manag Care Pharm. 2003;9(4):309-16.

20. Balkrishnan R, Rajagopalan R, Camacho FT, Huston SA, Murray FT, Anderson RT. Predictors of medication adherence and associated health care costs in an older population with type 2 diabetes mellitus: a longitudinal cohort study. Clin Ther. 2003;25:2958-71.

21. Hall JA, Summers KH, Obenchain RL. Cost and utilization comparisons among propensity score-matched insulin lispro and regular insulin users. J Manag Care Pharm. 2003;9(3):263-68.

22. Edlin M. External comparisons help MCOs get a handle on diabetes costs. Manag Health Care Exec. 2001;11:38-40.

23. Brown JB, Nichols GA, Glauber HS, Bakst AW, Schaeffer M, Kelleher CC. Health care costs associated with escalation of drug treatment in type 2 diabetes mellitus. Am J Health Syst Pharm. 2001;58:151-57.

24. Rosenzweig JL, Weinger K, Poirier-Solomon L, Rushton M. Use of a disease severity index for evaluation of health care costs and management of comorbidities of patients with diabetes mellitus. Am J Manag Care. 2002;8: 950-58.

25. Petitti DB, Contreras R, Ziel FH, Dudl J, Domurat ES, Hyatt JA. Evaluation of the effect of performance monitoring and feedback on care process, utilization, and outcome. Diabetes Care. 2000;23:192-96.

26. Stafford RS, Davidson SM, Davidson H, Miracle-McMahill H, Crawford SL, Blumenthal D. Chronic disease medication use in managed care and indemnity insurance plans. Health Serv Res. 2003;38:595-612.

27. Roblin DW, Platt R, Goodman MJ, et al. Effect of increased cost-sharing on oral hypoglycemic use in 5 managed care organizations: how much is too much? Med Care. 2005;43:951-59. 
28. Engelgau MM, Geiss LS, Manninen DL, et al. Use of services by diabetes patients in managed care organizations. Development of a diabetes surveillance system. CDC Diabetes in Managed Care Work Group. Diabetes Care. 1998;21:2062-68.

29. Lafata JE, Martin S, Morlock R, Divine G, Xi H. Provider type and the receipt of general and diabetes-related preventive health services among patients with diabetes. Med Care. 2001;39:491-99.

30. Koro CE, Bowlin SJ, Bourgeois N, Fedder DO. Glycemic control from 1988 to 2000 among U.S. adults diagnosed with type 2 diabetes. Diabetes Care. 2004:27:17-20.

31. Cohen FJ, Neslusan CA, Conklin JE, Song X. Recent antihyperglycemic prescribing trends for U.S. privately insured patients with type 2 diabetes. Diabetes Care. 2003;26:1847-51

32. Bowman L, Hayes R, Long S, Chang S, Crown W. Diabetes drug prescribing patterns in managed care. Poster presented at: 63rd Annual Meeting and Scientific Sessions of the American Diabetes Association; June 13-17, 2003; New Orleans, LA. Abstract 1108-P.

33. Boccuzzi SJ, Wogen J, Fox J, Sung JCY, Shah A, Kim J. Utilization of oral hypoglycemic agents in a drug-insured U.S. population. Diabetes Care. 2001;24: 1411-15.

34. Chen K, Chang EY, Summers KH, Obenchain RL, Yu-Isenberg KS, Sun P. Comparison of costs and utilization between users of insulin lispro versus users of regular insulin in a managed care setting. J Manag Care Pharm. 2005; 11(5):376-82.

35. Thiebaud P, Patel BV, Nichol MB. The effect of insulin treatment on health care utilization in type II diabetes [abstract]. Value Health. 2005;8:361. Abstract PDB29.

36. Johnson ES, Koepsell TD, Reiber G, Stergachis A, Platt R. Increasing incidence of serious hypoglycemia in insulin users. J Clin Epidemiol. 2002;55: 253-59.

37. Heaton A, Martin S, Brelje T. The economic effect of hypoglycemia in a health plan. Manag Care Interface. 2003;16:23-27.

38. Pharmaceutical Research and Manufacturers of America (PhRMA) and Fingland MJ. Diabetes study: many insured patients with diabetes do not receive medicine to help maintain health and control disease [press release]. PhRMA Report (April 2004): Examination and treatment patterns and effects of medication-taking behaviors among insured patients with diabetes. Available at: http://www.phrma.org/publications/policy/2004-04-19.958.pdf. Accessed June 30, 2005.

39.Curkendall S, Sarocco P, Goldberg GA, Patton M. Burden of non-adherence to oral antidiabetics [abstract]. Value Health. 2005;8:360. Abstract PDB26.

40. Lau DT, Nau DP. Oral antihyperglycemic medication nonadherence and subsequent hospitalization among individuals with type 2 diabetes. Diabetes Care. 2004:27:2149-53.

41. Menzin J, Langley-Hawthorne C, Friedman M, Boulanger L, Cavanaugh R. Potential short-term economic benefits of improved glycemic control: a managed care perspective. Diabetes Care. 2001;24:51-55.

42. Wagner EH, Sandhu N, Newton KM, McCulloch DK, Ramsey SD, Grothaus LC. Effect of improved glycemic control on health care costs and utilization. JAMA. 2001;285:182-89.

43. Shetty SS, Secnik K, Oglesby AK. Relationship of glycemic control to total diabetes-related costs for managed care health plan members with type 2 diabetes. J Manag Care Pharm. 2005;11(7):559-64.

44. Gilmer TP, O'Connor PJ, Rush WA, et al. Predictors of health care costs in adults with diabetes. Diabetes Care. 2005;28:59-64.

45. Oglesby AK, Secnik K, Barron J, Al-Zakwani I, Lage MJ. The association between diabetes related medical costs and glycemic control: a longitudinal analysis [abstract]. Value Health. 2005;8:356. Abstract PDB16.

46. Steffens B. Cost-effective management of type 2 diabetes: providing quality care in a cost-constrained environment. Am J Manag Care. 2000;6:(suppl 13) S697-S703
47. Sidorov J, Shull R, Tomcavage J, Girolami S, Lawton N, Harris R. Does diabetes disease management save money and improve outcomes? A report of simultaneous short-term savings and quality improvement associated with a health maintenance organization-sponsored disease management program among patients fulfilling health employer data and information set criteria. Diabetes Care. 2002;25:684-89.

48. Gilmer TP, O'Connor PJ, Manning WG, Rush WA. The cost to health plans of poor glycemic control. Diabetes Care. 1997;20:1847-53.

49. Goetzel RZ, Ozminkowski RJ, Villagra VG, Duffy J. Return on investment in disease management: a review. Health Care Financ Rev. 2005;26:1-19.

50. Parris ES, Lawrence DB, Mohn LA, Long LB. Sulfonylurea adherence is associated with Alc goal attainment in a managed care diabetes disease management program. Poster presented at: 64th Annual Scientific Sessions of the American Diabetes Association; June 4-8, 2004; Orlando, FL. Abstract 1187-P.

51. Hay JW. Appropriate econometric methods for pharmacoeconomic studies of retrospective claims data: an introductory guide. J Manag Care Pharm. 2005;11(4):344-48.

52. National Committee on Quality Assurance (NCQA). The state of health care quality (2003 report). Available at: http://www.ncqa.org/

Communications/News/sohc2003.htm. Accessed May 5, 2005.

53. Suh DC, Shin HC, Vo L, Valiyeva E, Barone JA. Prevalence of diabetes mellitus and treatment patterns based on classification of body mass index among adults [abstract]. Value Health. 2005;8:354. Abstract PDB8.

54. Karter AJ, Moffett HH, Liu J, et al. Achieving good glycemic control: initiation of new antihyperglycemic therapies in patients with type 2 diabetes from the Kaiser Permanente Northern California Diabetes Registry. Am J Manag Care. 2005;11:262-70.

55. Medak R, Lucas J, Ahmann A. Diabetes management of Medicare patients enrolled in managed care: a patient centered analysis. Paper presented at: 63rd Annual Meeting and Scientific Sessions of the American Diabetes Association; June 13-17, 2003; New Orleans, LA. Abstract 2264-PO.

56. Beaton SJ, Nag SS, Gunter MJ, Gleeson JM, Sajjan SS, Alexander CM. Adequacy of glycemic, lipid, and blood pressure management for patients with diabetes in a managed care setting. Diabetes Care. 2004;27:694-98.

57. Godley PJ, Maue SK, Farrelly EW, Frech F. The need for improved medical management of patients with concomitant hypertension and type 2 diabetes. Am J Manag Care. 2005;11:206-10.

58. Knight K, Badamgarav E, Henning JM, et al. A systematic review of diabetes disease management programs. Am J Manag Care. 2005;11:242-50.

59. Choe HM, Mitrovich S, Dubay D, Hayward RA, Krein SL, Vijan S. Proactive case management of high-risk patients with type 2 diabetes mellitus by a clinical pharmacist: a randomized controlled trial. Am J Manag Care. 2005;11:253-60.

60. Fitzner K, Fox K, Schmidt J, Roberts M, Rindress D, Hay J. Implementation and outcomes of commercial disease management programs in the United States: the Disease Management Outcomes Consolidation Survey. Dis Manag. 2005;8:253-64.

61. Wysowski DK, Armstrong G, Governale L. Rapid increase in the use of oral antidiabetic drugs in the United States, 1990-2001. Diabetes Care. 2003;26:1852-55.

62. Braunstein SN, White JR. Trends in the management of type 2 diabetes: an emerging role for insulin. J Manag Care Pharm. 2005;11(1)(suppl S-b):S2S11.

63. Chait J. Insulin usage continues to evolve. Diabetes Health. Available at: http://www.diabeteshealth.com/print,article,3117.html. Accessed July 5, 2005.

64. Close KL. Diabetes close up: BD/Novo 3Q3. Diabetes Close Up (newsletter). 2003;2:1-4. Available at: http://www.closeconcerns.com. Accessed June 30, 2005.

65. Koopman RJ, Mainous AG, Diaz VA, Geesey ME. Changes in age at diagnosis of type 2 diabetes mellitus in the United States, 1988 to 2000. Ann Fam Med. 2005;3:60-63. 
66. Geiss LS, Pan L, Betsy C, Benjamin S, Gregg E, Engelgau M. Recent changes in the incidence of diagnosed diabetes and in the characteristics of incident cases, United States 1997-2003. Poster presented at: 65th Annual Scientific Sessions of the American Diabetes Association; San Diego, CA; June 13, 2005. Abstract 997-P.

67. Hitti M. New diabetes cases soaring, obesity related. CDC: diabetes cases increased by $41 \%$ from 1997-2003 (press release, June 13, 2005). WebMD

Medical News. Available at: http://www.webmd.com/content/Article/107-

108477.htm. Accessed November 30, 2005.
68. Weinstock RS, Hawley G, Repke D, Feuerstein BL, Sawin CT, Pogach LM. Pharmacy costs and glycemic control in the Department of Veterans Affairs. Diabetes Care. 2004;27:B74-B81. 